\title{
Management of cervical spine deformity after intradural tumor resection
}

\author{
Andrei F. Joaquim, MD, PhD, ${ }^{1}$ and K. Daniel Riew, MD² \\ ${ }^{1}$ Neurosurgery Division, University of Campinas (UNICAMP), Campinas, São Paulo, Brazil; and 2Department of Orthopedics, \\ Columbia University, New York, New York
}

\begin{abstract}
Management of intradural spinal tumors requires posterior decompressive techniques. Cervical spine deformity secondary to sagittal and/or coronal imbalance after a laminectomy may result in significant cervical pain and functional deterioration, as well as neurological deficits in the most severe cases. In this paper, the authors discuss the management of cervical spine deformity after intradural tumor resection, with emphasis on the surgical strategies required to reestablish acceptable cervical spine alignment and to correct postoperative deformity. In general, after an oncological evaluation, assessing the alignment, extent, and flexibility of the deformity is mandatory before surgical planning. Rigid deformities require an osteotomy and, most often, combined approaches to restore cervical alignment. Flexible deformities can often be treated with a single approach, although a circumferential approach has its advantages.
\end{abstract}

http://thejns.org/doi/abs/10.3171/2015.5.FOCUS15134

KEY WORDS deformity; cervical; laminectomy; intradural; kyphosis; osteotomy

$\mathrm{P}$ OSTERIOR cervical approaches for the treatment of intradural spinal lesions, such as intramedullary or extramedullary tumors, require posterior decompressive techniques. Cervical spine deformity secondary to sagittal and/or coronal imbalance after a laminectomy may result in important cervical pain and functional deterioration, along with neurological deficits in the most severe cases., ${ }^{2,10,21}$ In general, the majority of deformities secondary to cervical laminectomy occur in the sagittal plane, resulting in cervical kyphosis..$^{9,14}$

Many risk factors have been related to a higher incidence of deformity after laminectomy. Probably the most important factors are young age, extension (larger) and location (junctional areas) of the laminectomy, concomitant resection of the facet joints (as occurs in nerve sheath tumor resection with lateral extension), a requirement for postoperative radiotherapy (e.g., in patients with malignant tumors), and the existence of preoperative cervical deformity., $5,17,20,21$ Potential preventive measures may include avoiding resection of the facet joints and performing laminoplasty instead of laminectomy and, in well-selected cases, concomitant instrumented arthrodesis. ${ }^{10,24,26}$ In addition, surgeons should be careful to not disrupt the extensor muscles of the neck and their attachments. Of these muscles, the most important is the semispinalis cervicis, and the most important insertion point of all cervical extensor muscles is into the spinous process of $\mathrm{C}-2$. Hence, a laminectomy of $\mathrm{C}-2$, or detachment of the muscles that insert into it, will nearly always result in cervical kyphosis. ${ }^{21}$

Conversely, in the absence of major risk factors for a postoperative deformity, it is not reasonable to perform a routine instrumented arthrodesis in the treatment of intradural tumors, because only a minority of patients who undergo laminectomy will develop a symptomatic postoperative deformity that requires treatment. ${ }^{1}$ Concomitant instrumented arthrodesis increases operative time and 
surgical costs, adds risk for morbidity after the tumorresection procedure, and must be considered carefully in well-selected cases. ${ }^{1}$

In this paper, we discuss the management of cervical spine deformity after intradural tumor resection, with emphasis on the surgical strategies required to reestablish acceptable cervical spinal alignment and to correct postoperative deformity.

\section{Epidemiology}

The incidence of postlaminectomy deformity depends on many variables, such as the studied population, the etiology of the intradural lesion (e.g., malignant vs benign), the surgical technique used (e.g., laminectomy, laminoplasty), the extension of the laminectomy, and the existence of preoperative deformity, among many others already discussed in the literature., ${ }^{7,85,17,27}$ The exact incidence of cervical kyphosis after surgery to treat an intradural tumor is not known. However, for younger patients, especially those younger than 18 years, some authors have reported that up to $50 \%$ of their patients had some progression of segmental spinal kyphosis or worsening of preexisting kyphosis after laminectomy for an intradural tumor. ${ }^{2}$ Potential reasons for the increased risk of deformities in children are the laxity of their ligamentous structures, the orientation of their facet joints (they are more horizontal than those of adults), and abnormal growth of their still-growing vertebral column caused by the removal of posterior elements. ${ }^{15,17,28,32,33}$ Patients with malignant intradural tumors who will need radiation therapy are also at a higher risk of postoperative deformity and may be candidates for instrumented fusion because radiation can decrease the potential of cartilage growth. In addition, radiation results in weakening of the vertebral column, which increases the risk of anterior or lateral wedging of the vertebrae. ${ }^{8}$ Finally, radiation results in damage to the soft tissues and extensor muscles, which further increases the risk of deformity.

\section{Diagnosis and Clinical Presentation}

Cervical deformity has been defined and categorized in numerous ways. Benzel ${ }^{3}$ has proposed a diagnosis of cervical kyphosis when the dorsal aspect of any vertebra from C-3 to C-6 crosses a line drawn from the posteroinferior aspect of the $\mathrm{C}-2$ body in the midsagittal plane to the posteroinferior aspect of the C-7 body. The normal lordotic curve of the cervical spine ranges from $20^{\circ}$ to $35^{\circ}$ from C-2 to C-7, but these angles depend on the method of measurement used and the patient's age. ${ }^{4,11}$ Approximately two-thirds of the weight-bearing axis lies posterior to the vertebral bodies, sustained by the posterior columns. ${ }^{10}$ After loss of the posterior ligamentous and bony structures, the weight-bearing axis shifts anteriorly, which results in loss of the normal cervical lordosis and alteration of the alignment to a straight and then finally kyphotic alignment.

The indications for performing surgical deformity correction depend on the intensity of the symptoms and the progression of the deformity. In asymptomatic patients, some mild deformity is acceptable, but when progression is evident radiologically and there is some risk of neurological deterioration, surgery is reasonable. ${ }^{10,14,31}$

Clinical symptoms of cervical deformity after intradural tumor surgery generally start after a period of temporary functional improvement. After some time, varying from weeks to even years, cervical pain can occur secondary to muscle fatigue from persistent strain, improving with rest or recumbence. Pain is generally the main symptom of postoperative deformity, followed by the deformity itself. Compression of the spinal cord in the kyphotic segment can cause new or recurrent neurological deficits, either from direct compression or from a stretch myelopathy. The deformity can even progress to its most severe form, a "chin-on-chest" deformity.

\section{Surgical Planning \\ Patients With Cervical Deformity Diagnosed Before Intradural Tumor Surgery}

It should be obvious that the primary goal for a patient with an intradural tumor and concomitant cervical deformity is to resect the intradural tumor completely, when feasible, such as with benign meningiomas or schwannomas and with some intramedullary tumors (e.g., ependymomas and hemangioblastomas). ${ }^{16,19}$ Oncological assessment and treatment take precedence over the deformity, because a poor oncological result usually leaves a greater potential for mortality or worsened morbidity. It should be noted that instrumentation for intradural tumors will affect the ability of postoperative surveillance MRI to detect tumor recurrence. This should be given consideration, especially for patients with tumors that require frequent MRI screening, and efforts to minimize the use of instrumentation should be made.

In the setting of preoperative deformity, the decision to perform tumor resection and deformity corrective surgery at the same time depends on the surgeon's preference and the patient's individual characteristics. The obvious advantages of a single-stage surgery include avoidance of additional procedures and a decrease in costs and the patient's anxiety related to prolonged treatment. In addition, reoperation in a patient who has previously undergone a laminectomy is usually more challenging than completing the decompression and instrumented fusion in one stage. Therefore, in the setting of mild or moderate preoperative deformity, tumor resection and concomitant deformity correction should be strongly considered. However, the advantage of staged approaches is the shorter initial procedure time, especially in challenging and complicated cases in which combined anterior and posterior approaches are required. If a patient who is undergoing tumor resection requires a prolonged operative time or is at high risk for neurological complication, a staged procedure may be a better option. Whenever possible, a laminoplasty is preferred over a laminectomy as long as the tumor resection would not be compromised, because laminoplasty makes the revision operation substantially easier and safer. ${ }^{24,27,31}$ If a laminectomy is necessary, one can replace the lamina and hold it in place with the miniplates used by hand surgeons. If that is not possible, closing the first layer of the soft tissues with a running, nonabsorbable, colored suture 

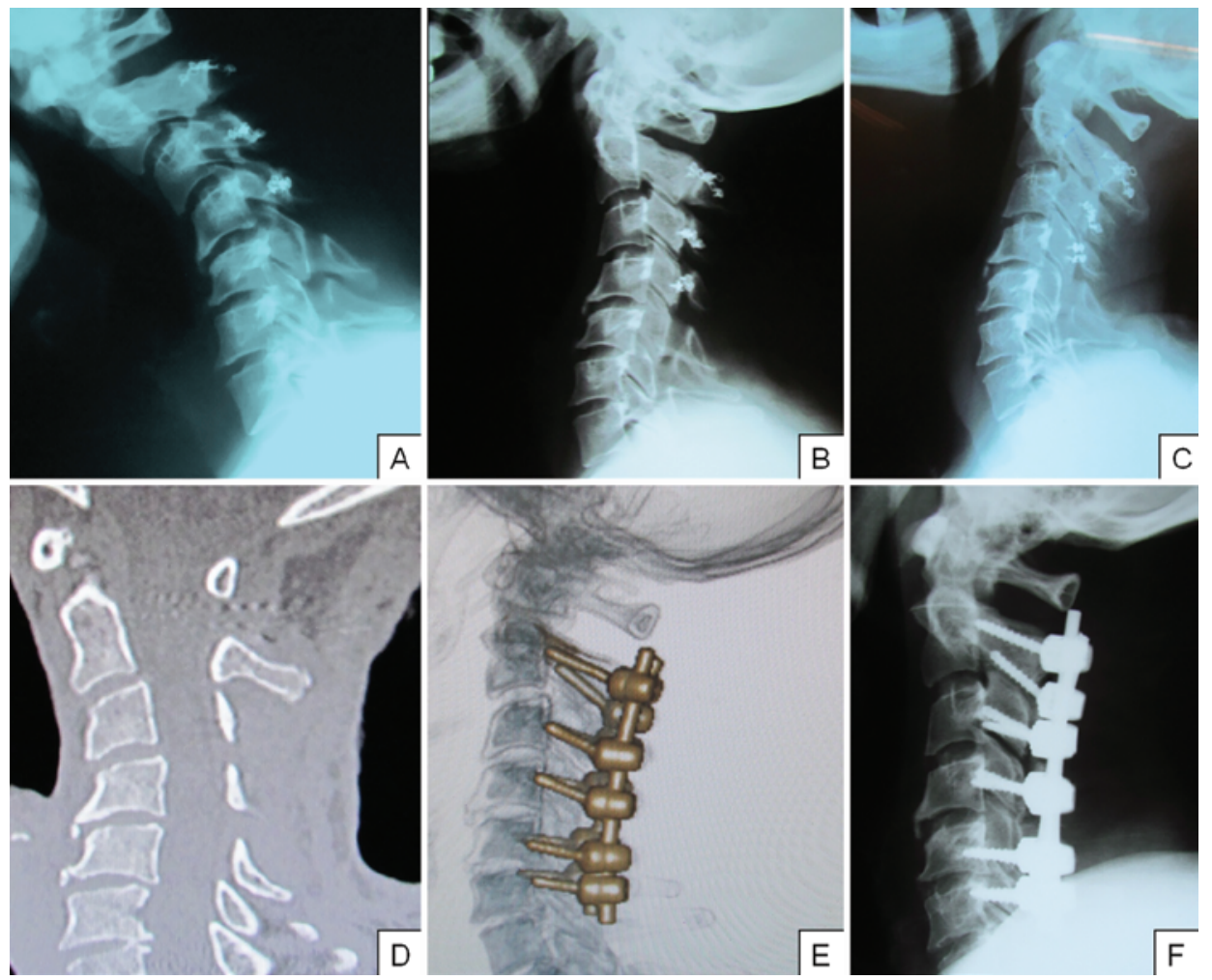

FIG. 1. A 45-year-old woman developed severe cervical pain with flexible C2-5 kyphosis approximately 1 year after a C2-4 laminoplasty for resection of an intradural schwannoma. Plain lateral cervical radiographs of the patient in the flexion (A), neutral (B), and extended (C) positions, with reducible kyphosis visible in C. D: Sagittal CT reconstruction showing kyphosis from C-2 to C-5. Final CT reconstruction $(\mathbf{E})$ and lateral cervical radiograph $(\mathbf{F})$ after a C2-6 instrumented fusion. The patient's pain decreased significantly after the procedure.

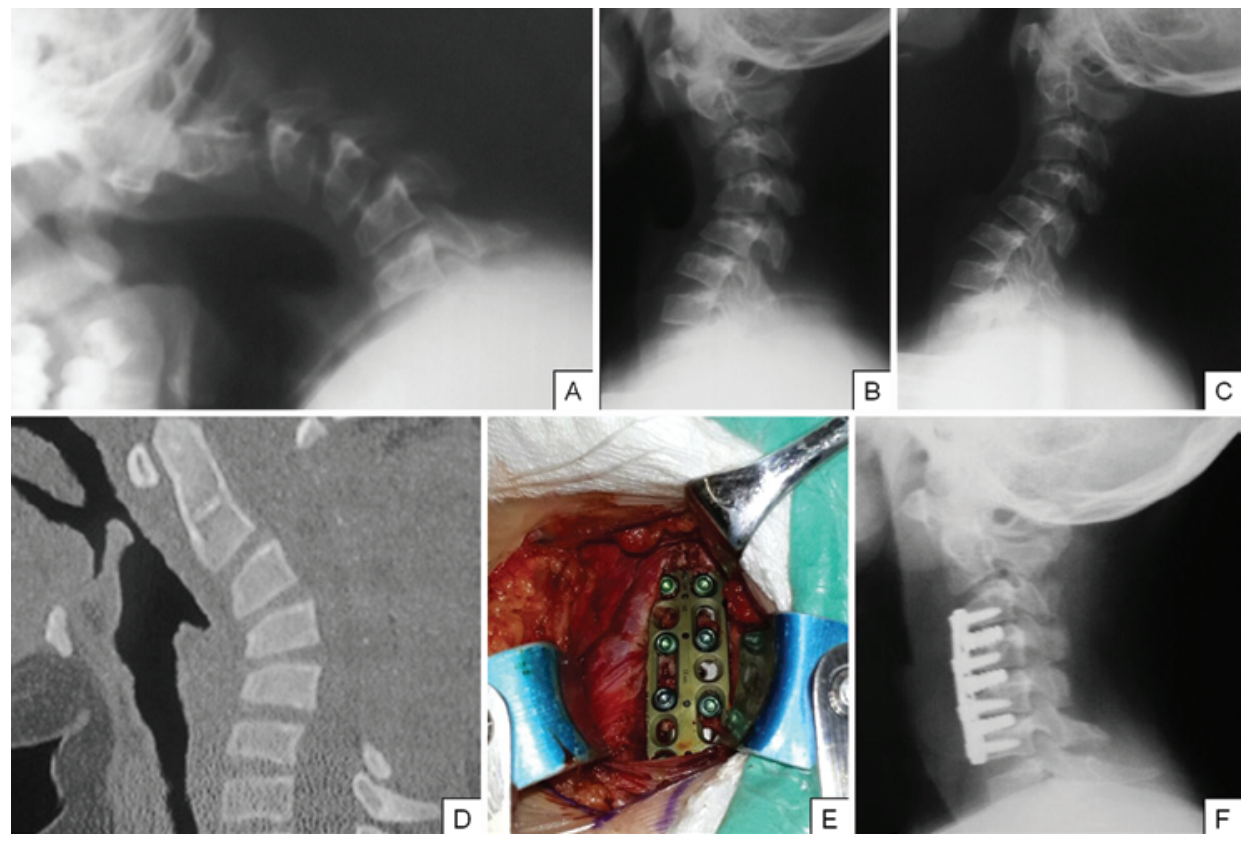

FIG. 2. A 10-year-old boy underwent a C2-5 laminectomy at another institution for an intradural ependymoma. Six months later, he developed C3-6 cervical kyphosis without ankylosed facet joints or anterior fusion, as shown in lateral cervical radiographs of the patient in the flexion (A), neutral (B), and extended (C) positions and in a sagittal CT reconstruction (D). He underwent a 3-level anterior cervical discectomy and fusion from C-3 through C-6 with plating (intraoperative picture [E]); concomitant intraoperative cervical traction with Gardner-Well tongs was used. He had acceptable cervical alignment 1 year after surgery, as shown in a lateral cervical radiograph $(\mathbf{F})$, and was clinically asymptomatic. 


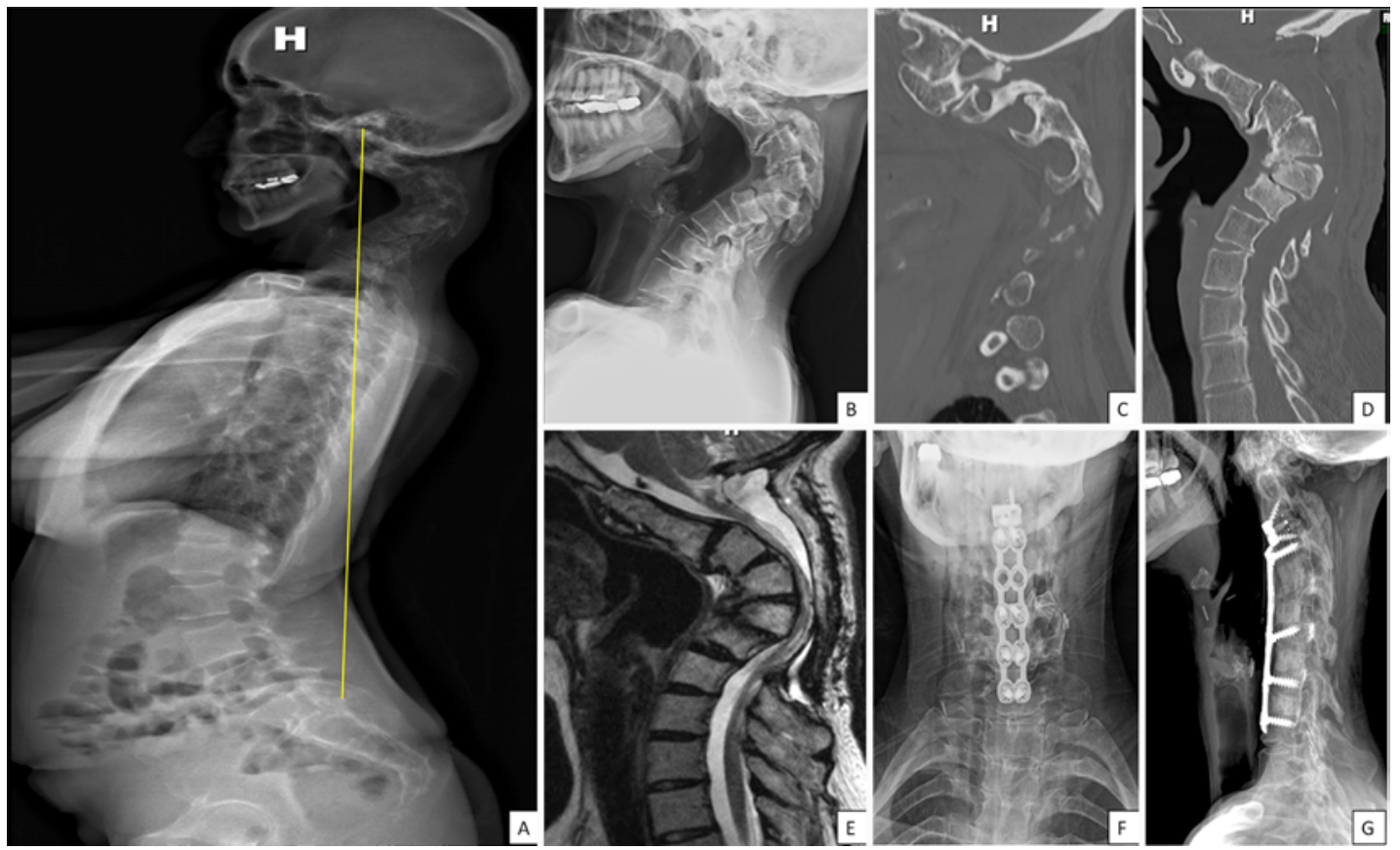

FIG. 3. A 45-year-old woman underwent a C4-6 laminectomy for treatment of an intradural astrocytoma when she was 15 years old. She developed severe cervical kyphosis with autofusion anteriorly and posteriorly. A: Standing EOS (EOS Imaging) radiographic image. B: Plain neutral-position lateral cervical radiograph. C and D: Sagittal CT scans demonstrating autofusions. E: Sagittal T2-weighted MR image showing spinal cord compression at the kyphotic levels and a patulous dura. The patient underwent anterior osteotomies at C3-5 and anterior cervical discectomy and fusions at C2-3 and C5-7. F and G: Anteroposterior and lateral cervical radiographs after surgery. Although the deformity was not fully corrected, the patient was happy with the results, and we were able to avoid what would have been a relatively complex posterior operation.

and closing the subsequent layer with an absorbable or noncolored suture will enable the surgeon to identify the last layer before the dura in the revision operation.

\section{Cervical Deformity That Develops After Intradural Tumor Resection}

As stated above, surgery is indicated for symptomatic patients or for those who are asymptomatic but have severe deformity progression and an increased risk for neurological deterioration.

The first step of surgical planning is to evaluate the extent of the kyphosis, from its cranial to its caudal segments, involved in the deformity. If a plumb line dropped from the tip of the dens falls anterior to the manubrium, the deformity at least partially involves the upper thoracic spine. ${ }^{29}$ Therefore, the correction must be carried down to a normal thoracic level. Other measurements include the C2-7 sagittal vertical axis, ${ }^{29}$ which measures the distance between 2 plumb lines: one dropped from the midvertebral body of $\mathrm{C}-2$ and the other from the posterior superior corner of the C-7 vertebral body. Distances greater than $4 \mathrm{~cm}$ are associated with poorer neck disability scores. ${ }^{29}$ Next, it is of paramount importance to determine if the kyphotic deformity is reducible. ${ }^{22,23}$ For that, dynamic plain lateral cervical radiographs and thin-cut CT scans are needed to establish the type of kyphosis involved: 1) rigid cervical kyphosis (anterior and/or posterior level fusions can be seen on a thin-cut CT image) or 2) flexible cervical kyphosis (the deformity is reducible as seen on a plain lateral cervical radiograph with the patient in an extended position, or no fusion levels can be seen on a CT image even if reduction cannot be seen in the lateral cervical radiograph with the patient in extension).

Often, patients will exhibit minimal motion on dynamic images because of pain or guarding. Comparing the cervical alignment of a patient between an MR image (in which the patient is supine for an extended period and tends to relax the neck) and a radiograph of the patient in the neutral lateral or flexion position will allow for a better assessment of fixed versus flexible deformities. In addition, for surgical planning, a CT scan is strongly recommended. The scan should be examined to determine if facet joints or disc spaces are fused or degenerated; the type, length, and diameter of fixation that can be used; and the extent of the previous bony resection. CT or MR angiography is also recommended for surgical planning. ${ }^{23} \mathrm{Fi}^{\mathrm{F}}$ nally, cervical MRI is also extremely helpful in the evaluation of spinal cord compression, myelomalacia, and syringomyelia, which may be important in surgical planning, and in determining the patient's prognosis..$^{22,23,25}$ If MRI is contraindicated, then a CT myelography is recommended.

\section{Rigid Cervical Kyphosis}

Patients with a rigid cervical kyphosis can undergo posterior facet fusion, an anterior fusion, or both. In the setting of ankylosed facet joints, there are 2 options for correcting the deformity via an anterior-only approach. First, it may be possible to achieve reasonable correction 


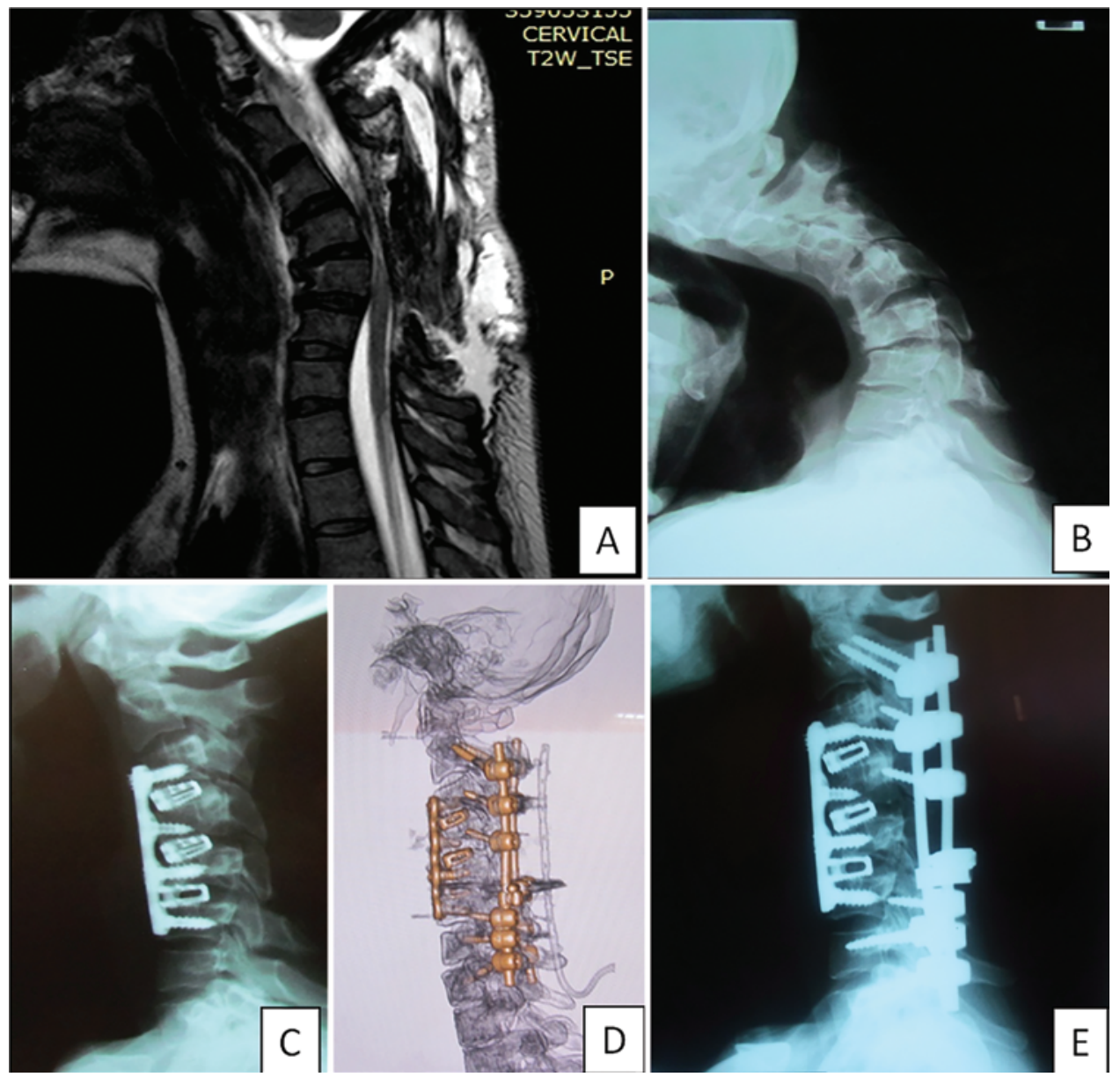

FIG. 4. A 27-year-old woman was treated for a cervical deformity after a multistage surgery for treatment of an intradural-extradural giant cervical neurofibroma. A: Sagittal T2-weighted MR image showing cervical kyphosis after total tumor resection and some degree of cord compression in the most kyphotic segment. B: Lateral cervical radiograph of the patient in a standing position showing severe postlaminectomy kyphosis. C: She underwent anterior discectomies and fusion at 3 levels (C3-4, C4-5, and C5-6) with plating and intraoperative traction, as shown in a lateral cervical radiograph. D and E: Final CT reconstruction and plain radiograph, respectively, after instrumented C2-T1 posterior fusion. The patient's cervical pain improved substantially after the procedure. From Rodrigues et al., Brazilian Journal of Neurosurgery 23:323-327, 2012. Reprinted with permission.

by leaving a kyphotic level alone and compensating for it by hyperlordosing the remaining levels. Second, one can actually break the facet fusion in most cases by using an anterior approach. ${ }^{22,23}$ To do so, after removing the entire anterior disc, 2 Caspar distractor pins or one set of pins and a vertebral body spreader are used to overdistract the space. Cage sizers can also be used to expand the space progressively. The fused facet joint will either bend or break with this technique, such that the deformity will be corrected. ${ }^{22}$ Alternatively, one can perform a posterior facet osteotomy followed by a posterior instrumented fusion. If only the facet is fused, a posterior operation alone will suffice.

If the patient has an anterior fusion without a posterior fusion, then an anterior osteotomy and correction will usually enable correction of the deformity. If the patient has a solid anterior and posterior fusion, the options include the anterior osteotomy described above, wherein one performs an anterior osteotomy followed by the distraction. Alternatively, one can perform a posterior pedi- cle subtraction osteotomy or a 3-stage anterior-posterioranterior or posterior-anterior-posterior osteotomy. ${ }^{23,30} \mathrm{~A}$ pedicle subtraction osteotomy involves releasing the posterior, middle, and anterior cervical column (decreasing the posterior column instead of increasing the anterior column). ${ }^{30}$ These procedures are complex and technically more demanding than combined approaches and should be performed only by surgeons with advanced skills. In a combined approach, one releases either the anterior or posterior column first, then releases and instruments the other side, and then returns to the original side for graft and instrument placement. Although technically the least demanding, this is the most time-consuming procedure in most surgeons' hands.

\section{Flexible Cervical Kyphosis}

No matter how rigid the kyphosis appears on dynamic images, in the absence of fused facets or disc spaces, it is by definition flexible because it is held in place only by 


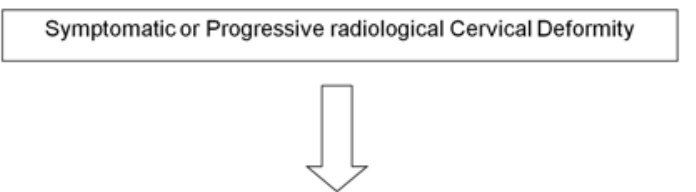

Evaluate the flexibility using dynamic lateral cervical plain radiographs and also a CT scan to assess posterior and / or anterior fusion
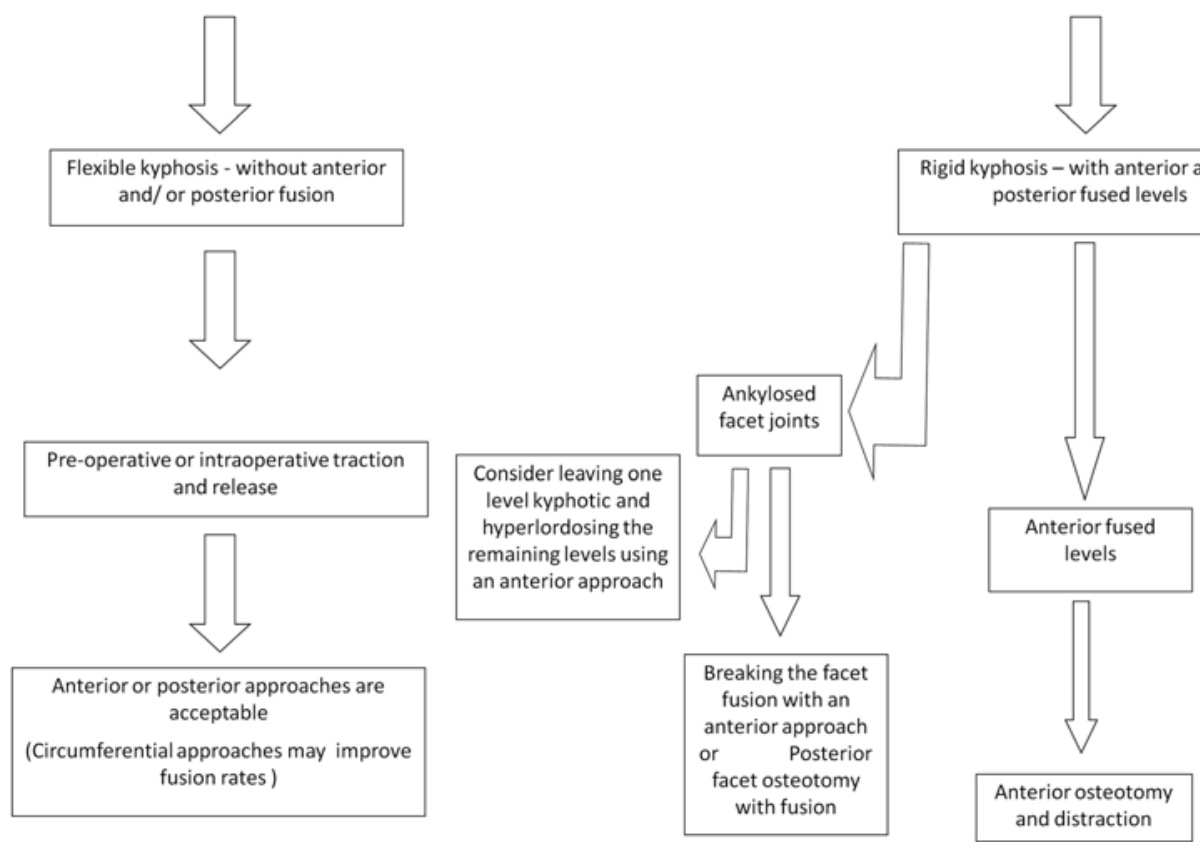

FIG. 5. Proposed algorithm for managing cervical deformity after intradural spinal tumor resection.

soft tissues. As such, it can be overcome by preoperative or intraoperative traction and release. Flexible cervical kyphosis can be treated either anteriorly or posteriorly. $22,23,30$

Cervical traction should be considered for all patients with a complex cervical deformity. For all flexible deformities, traction can help decrease the stiffness of the deformity and the degree of the kyphosis and can promote some muscle adaptation before the definitive surgical procedure. If there is a solid fusion, traction will not correct the deformity at the fused levels but may improve the correction at the nonfused levels. Gardner-Wells tongs can be applied in a patient while in a neutral supine position or even in a mildly extended cervical spine position (tongs are placed slightly anterior) after local asepsis and anesthetic infiltration. One can start with approximately $5 \mathrm{lbs}(2.5 \mathrm{~kg})$ and increase weight as tolerated (by approximately $2-5 \mathrm{lbs}$ ); neurological evaluations and lateral cervical radiographs should be used to assess the degree of correction. Weight can be increased rapidly, provided neurological and radiographic examinations are repeated, until approximately $20 \%$ of the patient's weight is achieved or the patient cannot tolerate further weight. ${ }^{18}$ Some surgeons prefer to forgo preoperative traction in favor of intraoperative correction, which prevents the need for preoperative admission and bedrest and their associated complications. In the end, it is the surgeon's preference because there is no evidence that one method is superior to the other.

Anteriorly, discectomies of the most kyphotic segments with lordotic grafts can increase the anterior column height and restore cervical lordosis. Plating is important for avoiding loss of deformity correction and graft migration. ${ }^{22,34}$ The need for posterior instrumentation and fusion depends on the extent of the deformity, the patient's bone quality, and the surgeon's preference. An exception for using a posterior approach before the anterior column reconstruction for patients with rigid cervical kyphosis without ankylosed facet joints is the presence of any posterior scar tissue or compression that may put the patient at risk from undergoing an anterior cervical approach with deformity correction. In our experience, this situation is extremely rare.

For selected patients in whom the anterior cervical spine is responsible for the deformity and there is some vertebral body compression of the spinal cord, anterior corpectomy(ies) can be performed. However, discectomies are better for improving cervical lordosis than corpectomies, and this should be considered when correcting the deformity and reestablishing the anterior column height. ${ }^{12,13}$ In the vast majority of cases, a discectomy and solid fusion will enable the cord to recover despite minor remaining compression.

One can also reconstruct the posterior tension band by using only an isolated instrumented posterior approach. It is important to include the most cranial to the most caudal level of the kyphosis, but additional levels may be included depending on many factors, such as bone quality, severity 
of the deformity, levels fused, the presence of facet arthrosis, or disc degeneration, among others.

Finally, strong consideration should be given to performing a circumferential procedure, especially when a patient has a severe deformity, osteoporosis, risk for pseudarthrosis (such as diabetes, smoking, or previous radiation), multiple previous operations, short life expectancy, poor fixation, or heavy narcotic dependency, or requires a multilevel osteotomy. ${ }^{6}$ A patient who undergoes revision multilevel fusion performed anteriorly or posteriorly after a previous laminectomy is at risk for pseudarthrosis. In addition, a patient who has had a second or third previous operation wants this to be his or her last spine operation. For those with a short life span, every operation that they have to undergo deprives them of precious time out of the hospital. Narcotic-dependent patients will complain of pain until the fusion solidifies, and a circumferential operation will result in faster fusing.

Four illustrative cases of surgery for the correction of cervical deformity after intradural tumor resection are presented in Figs. 1-4. An illustrative algorithm to help surgeons in clinical decision making for patients with a cervical deformity is presented in Fig. 5.

\section{Conclusions}

Cervical deformity after intradural tumor surgery can occur in a minority of patients and necessitate surgical intervention in the setting of important symptoms or when progression is evident radiologically. After an oncological evaluation, assessing the alignment, extent, and flexibility of the deformity is mandatory before surgical planning. Rigid deformities require osteotomies and, most often, combined approaches to restore cervical alignment. Flexible deformities can often be treated with a single approach, although there are advantages with the circumferential approach.

\section{References}

1. Anakwenze OA, Auerbach JD, Buck DW, Garg S, Simon SL, Sutton LN, et al: The role of concurrent fusion to prevent spinal deformity after intramedullary spinal cord tumor excision in children. J Pediatr Orthop 31:475-479, 2011

2. Bell DF, Walker JL, O'Connor G, Tibshirani R: Spinal deformity after multiple-level cervical laminectomy in children. Spine (Phila Pa 1976) 19:406-411, 1994

3. Benzel EC: Biomechanics of Spine Stabilization. Rolling Meadows, IL: American Association of Neurological Surgeons, 2001, p 526

4. Borden AG, Rechtman AM, Gershon-Cohen J: The normal cervical lordosis. Radiology 74:806-809, 1960

5. Butler JC, Whitecloud TS III: Postlaminectomy kyphosis. Causes and surgical management. Orthop Clin North Am 23:505-511, 1992

6. Carreon L, Glassman SD, Campbell MJ: Treatment of anterior cervical pseudoarthrosis: posterior fusion versus anterior revision. Spine J 6:154-156, 2006

7. Cattell HS, Clark GL Jr: Cervical kyphosis and instability following multiple laminectomies in children. J Bone Joint Surg Am 49:713-720, 1967

8. de Jonge T, Slullitel H, Dubousset J, Miladi L, Wicart P, Illés $\mathrm{T}$ : Late-onset spinal deformities in children treated by laminectomy and radiation therapy for malignant tumours. Eur Spine J 14:765-771, 2005
9. Deutsch H, Haid RW, Rodts GE, Mummaneni PV: Postlaminectomy cervical deformity. Neurosurg Focus 15(3):E5, 2003

10. Fassett DR, Clark R, Brockmeyer DL, Schmidt MH: Cervical spine deformity associated with resection of spinal cord tumors. Neurosurg Focus 20(2):E2, 2006

11. Gore DR, Sepic SB, Gardner GM: Roentgenographic findings of the cervical spine in asymptomatic people. Spine (Phila Pa 1976) 11:521-524, 1986

12. Han YC, Liu ZQ, Wang SJ, Li LJ, Tan J: Is anterior cervical discectomy and fusion superior to corpectomy and fusion for treatment of multilevel cervical spondylotic myelopathy? A systemic review and meta-analysis. PLoS ONE 9:e87191, 2014

13. Herman JM, Sonntag VK: Cervical corpectomy and plate fixation for postlaminectomy kyphosis. J Neurosurg 80:963-970, 1994

14. Lonstein JE: Post-laminectomy kyphosis. Clin Orthop Relat Res (128):93-100, 1977

15. Lunardi P, Licastro G, Missori P, Ferrante L, Fortuna A: Management of intramedullary tumours in children. Acta Neurochir (Wien) 120:59-65, 1993

16. Joaquim AF, Almeida JP, Dos Santos MJ, Ghizoni E, de Oliveira E, Tedeschi H: Surgical management of intradural extramedullary tumors located anteriorly to the spinal cord. J Clin Neurosci 19:1150-1153, 2012

17. Joaquim AF, Cheng I, Patel AA: Postoperative spinal deformity after treatment of intracanal spine lesions. Spine $\mathbf{J}$ 12:1067-1074, 2012

18. Joaquim AF, Patel AA: Subaxial cervical spine trauma: evaluation and surgical decision-making. Global Spine J 4:63-70, 2014

19. Joaquim AF, Santos MJ, Tedeschi H: Surgical management of intramedullary spinal ependymomas. Arq Neuropsiquiatr 67:284-289, 2009

20. Kaptain GJ, Simmons NE, Replogle RE, Pobereskin L: Incidence and outcome of kyphotic deformity following laminectomy for cervical spondylotic myelopathy. J Neurosurg 93 (2 Suppl):199-204, 2000

21. Katsumi Y, Honma T, Nakamura T: Analysis of cervical instability resulting from laminectomies for removal of spinal cord tumor. Spine (Phila Pa 1976) 14:1171-1176, 1989

22. Kim HJ, Piyaskulkaew C, Riew KD: Anterior cervical osteotomy for fixed cervical deformities. Spine (Phila Pa 1976) 39:1751-1757, 2014

23. Kim HJ, Piyaskulkaew C, Riew KD: Comparison of SmithPetersen osteotomy versus pedicle subtraction versus anterior-posterior osteotomy types for the correction of cervical spine deformities. Spine (Phila Pa 1976) 40:143-146, 2015

24. McGirt MJ, Chaichana KL, Atiba A, Bydon A, Witham TF, Yao KC, et al: Incidence of spinal deformity after resection of intramedullary spinal cord tumors in children who underwent laminectomy compared with laminoplasty. J Neurosurg Pediatr 1:57-62, 2008

25. McMaster MJ: Osteotomy of the cervical spine in ankylosing spondylitis. J Bone Joint Surg Br 79:197-203, 1997

26. Meyer NJ, Flatley TJ, Dunn DD: Superiorly based laminoplasty in children: average 6.8-year follow-up of 21 patients. J Spinal Disord Tech 16:156-162, 2003

27. Montano N, Trevisi G, Cioni B, Lucantoni C, Della Pepa GM, Meglio M, et al: The role of laminoplasty in preventing spinal deformity in adult patients submitted to resection of an intradural spinal tumor. Case series and literature review. Clin Neurol Neurosurg 125:69-74, 2014

28. Sciubba DM, Chaichana KL, Woodworth GF, McGirt MJ, Gokaslan ZL, Jallo GI: Factors associated with cervical instability requiring fusion after cervical laminectomy for intradural tumor resection. J Neurosurg Spine 8:413-419, 2008 
29. Tang JA, Scheer JK, Smith JS, Deviren V, Bess S, Hart RA, et al: The impact of standing regional cervical sagittal alignment on outcomes in posterior cervical fusion surgery. Neurosurgery 71:662-669, discussion 669, 2012

30. Wollowick AL, Kelly MP, Riew KD: Pedicle subtraction osteotomy in the cervical spine. Spine (Phila Pa 1976) 37:E342-E348, 2012

31. Yao KC, McGirt MJ, Chaichana KL, Constantini S, Jallo GI: Risk factors for progressive spinal deformity following resection of intramedullary spinal cord tumors in children: an analysis of 161 consecutive cases. J Neurosurg 107 (6 Suppl):463-468, 2007

32. Yasuoka S, Peterson HA, MacCarty CS: Incidence of spinal column deformity after multilevel laminectomy in children and adults. J Neurosurg 57:441-445, 1982

33. Yeh JS, Sgouros S, Walsh AR, Hockley AD: Spinal sagittal malalignment following surgery for primary intramedullary tumours in children. Pediatr Neurosurg 35:318-324, 2001
34. Zdeblick TA, Bohlman HH: Cervical kyphosis and myelopathy. Treatment by anterior corpectomy and strut-grafting. J Bone Joint Surg Am 71:170-182, 1989

\section{Author Contributions}

Conception and design: both authors. Acquisition of data: both authors. Analysis and interpretation of data: both authors. Drafting the article: both authors. Critically revising the article: both authors. Reviewed submitted version of manuscript: both authors. Approved the final version of the manuscript on behalf of both authors: Joaquim. Study supervision: both authors.

\section{Correspondence}

Andrei F. Joaquim, UNICAMP, Department of Neurology, Cidade Universitária Zeferino Vaz, Campinas 13087-460, São Paulo, Brazil. email: andjoaquim@yahoo.com 